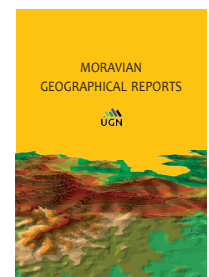

MORAVIAN GEOGRAPHICAL REPORTS

The Czech Academy of Sciences, Institute of Geonics

journal homepage: http://www.geonika.cz/mgr.html

doi: https://oi.org/10.2478/mgr-2020-0018

\title{
Mobile phone data in studying urban rhythms: Towards an analytical framework
}

\author{
Martin ŠVEDA ${ }^{a, b *}$, Michala SLÁDEKOVÁ MADAJOVÁ ${ }^{b}$, Peter BARLÍK ${ }^{\mathrm{c}}$, \\ František KRIŽAN ${ }^{a}$, Pavel ŠUŠKKA ${ }^{b}$
}

\begin{abstract}
Mobile phone data are considered one of the most promising information sources for monitoring and measuring the spatio-temporal activities of the population. Today, large-volume mobile phone datasets are widely applied to monitor the daily life of the urban population and to examine the structuring of the urban environment. In this paper, we discuss and develop a methodological procedure that uses such data to observe temporal differences of human presence in Bratislava, Slovakia. The study is based on a large-scale dataset of hourly records of signalling exchanges (VLR data) from all major mobile network operators in Slovakia. The records of the mobile network infrastructure are used as a suitable proxy variable for complex human activity at the city level, in the sense that they capture various kinds of spatial practices, and not only some specific activities (work cycle of a given locale, shopping, and similar events). Such an approach allows the classification of urban space using diurnal logs activity curves of mobile network cells. Six temporality types in Bratislava were identified, which may be designated as examples of an urban chronopolis. The results show the potential of the proposed method for measuring place temporality in cities and monitoring the urban environment with geo-referenced mobile phone data.
\end{abstract}

Keywords: mobile phone data, diurnal rhythms, urban timespace, chronopolis, Bratislava, Slovakia

Article history: Received 10 April, Accepted 5 October 2020, Published 31 December 2020

\section{Introduction}

The availability of spatial and temporal data through various location-aware technologies has led to increasing interest in time geography in the past decade (Sui, 2012). Mobile phone data are one of the most promising data sources to monitor daily life and short-term processes because of their ability to capture population movement patterns and trajectories (Deville et al., 2014; Kang et al., 2012).

These large volume datasets are considered a valuable indicator of human presence and provide us with the opportunity to track spatial mobility patterns at an individual level (Ahas et al., 2010; González et al., 2008; Novák and Temelová, 2012; Song et al., 2010), as well as to map the movement and activity of the population by using aggregated data (Ma et al., 2019; Ratti et al., 2006; Reades et al., 2009; Yuan and Raubal, 2016). The mobile positioning has found considerable use in mobility and traffic studies (Järv et al., 2012; Calabrese et al., 2011), but also in areas such as crisis management (Bengtsson et al., 2011), the monitoring of foreign tourist visits (Ahas et al., 2008; Šveda et al., 2019), or the spread of epidemics (Weselowski et al., 2012). Urban space and dynamic processes in cities are particularly of central interest, where the usefulness of mobile phone-based data has been demonstrated (Calabrese et al., 2011; Csáji et al., 2013; Nemeškal et al., 2020; Ratti et al., 2006; Sagl et al., 2014; Slim and Ahas, 2014).

Calls to study the diurnal variations of the population in urban localities from the viewpoint of the time geography paradigm were made decades ago (Bromley et al., 2003; Goodchild and Janelle, 1984; Muller, 1982; Taylor and Parks, 1975), but technological advances in mobile communications have brought new challenges in revealing time-space changes in population distribution. The ability to monitor daily movements for any time-period has opened new horizons in studying everyday urbanism and urban rhythmicity. Several attempts to include temporal aspects

\footnotetext{
${ }^{a}$ Department of Regional Geography, Protection and Planning of the Landscape, Faculty of Natural Sciences, Comenius University in Bratislava, Slovakia (*corresponding author: M. Šveda, e-mail: martin.sveda@uniba.sk)

${ }^{\mathrm{b}}$ Institute of Geography of the Slovak Academy of Sciences, Bratislava, Slovakia

${ }^{\mathrm{c}}$ Market Locator SK, Bratislava, Slovakia
} 
of urban life using mobile phone data have explored spatiotemporal movements of population and associated urban or suburban rhythms (Ahas et al., 2015; Ma et al., 2019; Nemeškal et al., 2020; Xia et al., 2018). Previous research has shown that mobile positioning allows us to study rhythmicity more precisely than using traditional methods such as questionnaires or travel diaries. A promising feature is the possibility of conducting population-wide research with robust samples that may open new perspectives in studying the spatio-temporal behaviours of urban inhabitants and reveal patterns of urban life.

This analysis is based on unique sources of data. Instead of the more commonly-used call detail records log files (CDR data), which are generated by the mobile network only at the time of performing a telecommunication activity (e.g. call, message or data streaming), our analysis works with the dataset of aggregated signalling exchange records between mobile phone and Base Transceiver Stations (BTS) from all major mobile network operators in the area. The visitor location register (VLR) data enables us to monitor the time-space record of mobile phone users, no matter how an individual uses her/his phone. This is particularly important with respect to the changes in mobile phone usage among different population subgroups (within a national population, as well as between different countries). The primary objective of this paper is to develop and discuss a methodological procedure that uses longitudinal signalling exchange data of mobile network operators, to observe temporal differences of human presence in urban space.

The advantage of the VLR data source is in its ability to include almost complete diurnal variations of population in urban space, as it captures differentiated mobilities and time-space strategies. By using VLR data we can monitor not only the work- and home-related movements, but also capture 'invisible' routine activities and movements which fill the timespace. This goes beyond the usual geographic explanations based on work-home trajectories. Analysing the VLR data we are getting closer to investigate the temporality related to a concrete place. This brings us to the concept of the chronotope as the unique combination of a specific place and specific time (Folch-Serra, 1990; Crang, 2001). Following the work of Czech geographers (Mulíček et al., 2015, 2016; Osman and Mulíček, 2017), place may be understood as a specific timing space composed of multiple rhythms. According to the nature of its temporality, it is possible to identify areas with analogous rhythmicity. On this basis, urban space may be classified into specific types of temporality. This study's second objective is to identify such different types of daily rhythms in the Bratislava city area. Specifically, we want to discuss the following research questions:

- How can we utilise VLR data for the identification of local-level diurnal rhythms?

- Does the collective behaviour of mobile phone users and their daily routines in the city form a specific place temporality?

- What does a specific composition of local rhythms say about the urban environment and the character of the everydayness of its inhabitants?

\section{Theoretical background}

\subsection{Urban rhythmicity}

Ever since Torsten Hägerstrand (1970) proposed a Time Geography, the daily rhythms of city everydayness have been studied by researchers in order to better understand the quality of urban life. The relationships of time and space in the urban environment offer a wide range of topics and interpretations (Ahas et al., 2010; Calabrese et al., 2010; Edensor, 2012; Goodchild and Janelle, 1984; Mulíček et al., 2015; Mulíček and Osman, 2018; Muller, 1982; Ratti et al., 2006), but we will concentrate on the understanding of a city as rhythmic compositions. This means interpreting the places not as static, but more like an action or event (Crang, 2001; Paiva, 2016).

In studying urban rhythmicity there are two theoretical traditions: Lefebvre's rhythmanalysis and Bakhtin's concept of chronotope (Osman and Mulíček, 2017).

Among the works framed by time-space duality and its dimensions, the contribution of French philosopher and sociologist Henri Lefebvre is probably the most influential. According to Lefebvre, everywhere where there is an interaction between a place, a time and an expenditure of energy, there is a rhythm (Lefebvre, 2004, p. 15). It is actual location and the materialisation of time through rhythm that makes rhythm analysis interesting for analytical use. Rhythm is not the object of analysis, it is itself an analytical tool that allows the research subject to be approached holistically as an 'open totality' (Lefebvre et al., 1996, p. 230).

Lefebvre's (2004) approach to rhythmanalysis could be used as a new operational approach for multiple versions of time geography (Sui, 2012, p. 12), as an indicator to measure functional diversity, and as a tool to evaluate the quality of urban space (Ahas et al., 2010). Since the city is made up of people and their activities (Wirth, 1938), research into urban rhythms has been closely related to the concept of everyday life. One can recognise rhythms, perceived in the form of regular temporal patterns of activities or practices, everywhere in everyday urban life. Rhythms involve interaction between people and spaces, which respond to the morphology of the spaces. Thus, urban rhythms are always polyrhythmic in the sense of rhythms with various speeds, trajectories and practice (Lefebvre, 2004). In this sense, urban polyrhythms are a composition of different human activities in specific localities over a specific time. It is obvious that the timing of daily human activity may vary among different parts of the city, and the nature of space-time trajectories may be (and it is) dissimilar. The framework enabling the study of the dynamic aspects of spatiotemporal organisation and to capture the polyrhythmic nature of an urban place, is the concept of chronotope.

The concept of chronotope was initially introduced in the 1930 s by Mikhail Bakhtin, the Russian philosopher, to describe the way literature represents time and space. In his inspiring work, he says that it is impossible to understand place without time and time without place (Bakhtin, 2002, pp. 15-16). According to Bakhtin, whatever is looked at is surrounded by the backdrop provided by the chronotope's time-space coordinates, where temporal and spatial determinations are inseparable from one another (Bakhtin, 1981). While Bakhtin utilises this approach in the analysis of literary narratives, Folch-Serra (1990) makes it relevant to geographical discourses by extrapolating the chronotope as a connection between space and time, characterised by the reversibility of moments in a temporal sequence, and by their interchangeability in space. The advantage of the chronotope lies in the fact that neither space nor time is privileged: chronotopes are places of intersection of temporal and spatial sequences (FolchSerra, 1990, p. 261). 
The concept that directly integrates Bakhtin's chronotope and Lefebvre's rhythmanalysis was introduced by Crang (2001), who understands the chronotope as a unity of a specific temporality associated with a specific place. The temporality of place is conceived as a unique combination of various rhythms, and a place is perceived not necessarily at a singular time but a spatially- bounded constellation of temporalities. By employing the chronotope, the locality can be grasped not only in a spatial/graphical way as a delimited piece of space, but also in a spatio-temporal way (graphically and narratively) as a timed, rhythmised place (Osman and Mulíček, 2017, p. 48). Thus, chronotopes refer to the ways in which space and time are always bound together, as well as to the particular forms in which such conjoined space-time is engendered, experienced and ordered in historically and geographically differentiated social life (Howell and Beckingham, 2015, p. 935). Similarly, Remm and Kasemets (2019) perceive the chronotope not only as a concept of a spatio-temporal organisation but also as an approach to experience and to interpret landscapes. Grasping the analytical construct of chronotope into more topologically-oriented view, R. Osman and O. Mulíček (2017) offer a space-time conceptualisation of a place for which they use the term of chronopolis, originally developed by M. Laguerre (Laguerre, 2003). Osman and Mulíček (2017) have linked this concept to the city-scale level by combining the polyrhythmias of individual places (chronotopes) into equally rhythmic but spatially dislocated polyrhythmias. They argue that the character of a place is determined not only by what is in that place, but by synchronisation with other places through rhythms of over-local scope. Their intention is to catch rhythmic analogies within a set of spatially dislocated urban chronotopes. The chronotopes attached to different localities but showing analogical rhythmic profiles represent a chronopolis (Osman and Mulíček, 2017, p. 49). In such a framework, the city is organised in specific types of temporality.

The chronopolis in this article is used to describe a common polyrhythmia of individual urban localities represented as urban grids - the basic spatial unit under investigation. This polyrhythmia is expressed by the diurnal course of city users recorded at the cell-level of a mobile network infrastructure. In this case, the attention is on the presence (or absence) of permanent city users as the most important element constituting the timespace character of a place - rhythmised place. The power of mobile phone data does not lie only in detecting the absence/presence of urban dwellers, but it allows us to study more deeply the rhythmic composition of an urban landscape.

\subsection{Detecting urban rhythms with mobile phone data}

The framework allowing researchers to capture the polyrhythmic nature of urban space can be approached from different angles and using various data sources. One of the most common sources are the call detail records log files (CDR data), that arise from any activity of a mobile phone with a mobile network connection and are routinely collected by cellular network providers. Diurnal call activity curves based on CDR data are extensively used in research (Ahas et al., 2015; Isaacman et al., 2011; Järv et al., 2012; Kang et al., 2012; Ratti et al., 2006; Sagl et al., 2014), but they do have some limitations. Mobile phones are used irregularly during the day and among different subgroups of the population, based on socio-economic characteristics as well as attitudes, lifestyles or habits (Castells et al., 2006). This makes CDR data sparse in time because they are generated only when a phone engages in a voice call, text message or data transmission.
Another approach is based on a (random) sample of mobile phone users, supported by a detailed questionnaire of participants' diurnal activities (Ahas et al., 2010; Novák and Temelová, 2012). Building upon this practice, we can capture the space-time movements and daily rhythms of individuals and examine the connections of urban users with different time-functions in different locations. Problems related to this method are linked to the representative nature of the sample, the coupling of participants' reports and trajectories, and privacy issues. Collecting such data for a large number of individuals is not a simple task. Moreover, the time-space trajectories are not easily adaptable for nation-wide mapping. The key problem lies in the extrapolation of networkbased samples for the whole population, and the correct interpretation of the resulting time-space differentiation. Such a rather unclear method of extrapolation is also a common feature in many single mobile network operatorbased approaches.

One relatively common feature of various mobile-networkbased approaches is the 'blurry' aspect of mobile phone data utilisation. The characteristics of mobile phone log origins and their processing, the technique of positioning (the BTS position/centroid of radiation polygon), the queries to extract meaningful locations (e.g. home and work localisation) or the spatial aggregation of cell-based data into territorial and administrative units, are hidden behind the data processing of the data provider. The 'black box' character of some mobile phone-based analyses raises questions about research reliability and validity. Clearly, the confusion is a consequence of privacy issues and the precautions of mobile network operators (MNOs). As researchers cannot directly access MNOs' strictly protected databases, there is an 'intermediator' which prepares queries for end users such as companies, governments or scientists. On the one hand, ensuring secure access to data through a data processing company provides a unique opportunity to exploit the potential of mobile phone localisation data, while maximising the anonymity of their users. On the other hand, the researchers lose control on the whole process of data processing. Even so, by jointly analysing the whole signalling exchange of all major MNOs, we want to overcome abovementioned limitations and bridge the trust gaps.

There are several advantages that support the use of mobile localisation in analysing urban rhythms. The robustness of mobile phone datasets can play an important role in the description of the polyrhythmia of individual urban places (chronotopes), as these new data streams provide an unparalleled picture of human activity and spatial shifts, which until recently have been very difficult to quantify on timescales relevant to the local level. Another advantage is the multi-scalar nature of mobile network data, as the granularity of mobile cells enables the city to be perceived as a set of chronotopes bound into a network. The ubiquity and standardised nature of mobile infrastructure create a longterm framework to monitor the spatial variability of the population at a high spatial and temporal resolution (Ratti et al., 2006; Reades et al., 2009). Raw mobile phone data, however, are not enough for any attempt to target a more holistic interpretation of urban chronotopes/chronopoles. Producing high-level knowledge from the low-level features (time-space location) of raw data requires additional contextual information (Grinberger and Shoval, 2015). Yet, with increasing connectivity, the mobile phone datasets facilitate a more comprehensive data source by applying geotagged social-networks-related content (Crooks et al., 2015; Tu et al., 2017). Coupling semantic information with mobile 
phone data is not a straightforward task, although it does offer an approach to reveal the evolving nature of urban living as rhythmic composition. Until that happens, we can think through the topology and texture of urban temporality using fine-grained data of individual daily human activity from the MNOs' visitor location registers.

\section{Data and methods}

In this paper, we present a procedure for analysing the dynamics of daily routines of city users by using longitudinal signalling exchange data (VLR data) from a mobile network. These data are automatically generated records produced by the mobile network at regular checks (pings) on connected devices. Individual BTS stations send a signal to all available and connected devices at regular intervals (defined by area/ operator). Based on its location and network utilisation, a specific BTS station is determined which will provide the signal to a particular device, thus ensuring the best coverage for each device within range. Preference of connection is given to an antenna with a more advanced transmission technology over one with a stronger signal (which may not be the closest in distance). At a given time, the VLR records the cell-level locations of all mobile devices, both active and idle. The observation of VLR records provides an instantaneous description of the location of all mobile devices at cell level. Every mobile device generates a log at each change of the BTS station, generating tens to hundreds of logs per day. In addition to the more commonly used CDR data, the VLR data enables us to monitor the time-space record of the mobile phone user no matter how an individual uses her/ his phone. This is particularly important considering the changes in mobile phone usage. While in the past we have used mobile phones mainly for voice calls and SMS messages, currently this use is diminished in favor of data services (social networks, instant chat, etc.) and passive use of the phone (e.g. various applications which do not require an active interaction).
The data used in this study were collected within the telecommunication network of the three major mobile network operators in Slovakia, capturing more than 330 million logs of 928,086 mobile network users (unique phone IDs), which have been monitored in Bratislava (Slovakia, approximately 430,000 inhabitants). Mobile network localisation data were recorded in the 14-days period from 26.11.2018 to 9.12.2018 (a typical period which did not correspond with any national or school holidays). The whole dataset, however, was not suitable for direct analysis. The fundamental challenge was to reject phone records of irregular city users (visitors) or of random temporality. The present framework is based on the concept of the so-called anchor-points (Ahas et al., 2010), which are represented as the main nodes of human activities that form the skeleton of daily movements. Using a suitable algorithm, we can extract the information about the basic anchor points of 'home' and 'work' from the mobile operator's network. In practice, it is mainly about identifying places (cell coverage areas) of most frequent day- and night-time localisation. Data on the concentration of day and night localisation allow us not only to specify the spatial distribution of the population but also to extract data about the expected daily transportation flows.

The procedure for the estimation of the temporal structure for a given population grid consists of the following steps (see also Fig. 1):

1. First, the cell footprint is derived from antenna configuration parameters (height, tilt, beam-width) in combination with cell tower location. This spatial information associated with the cell is reduced to a cell centroid. Due to the high level of sensitivity of such data, this procedure is managed by mobile network operators. No cell footprint, nor the location of the cell tower or cell size data are available;

2. In the second step, the number of mobile phone users (unique phone IDs) is extracted at each BTS tower, whose radiation polygon serves a part of the monitored

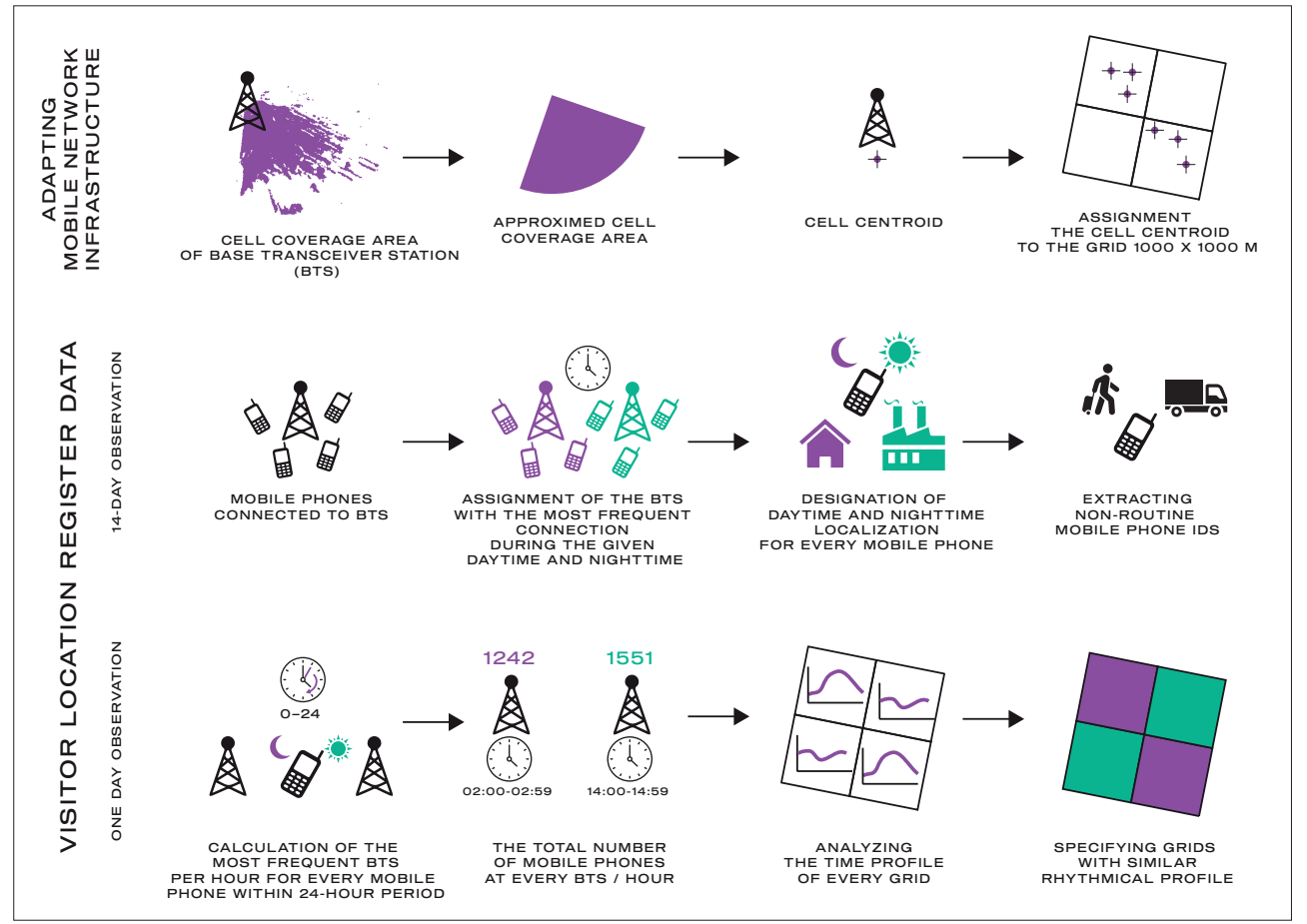

Fig. 1: Procedures for the temporal structure analysis using network-based localisation in the mobile network (visitor location register data)

Source: authors' conceptualisation 
territory. Besides traditional CDR data sets we used the VLR data, which represents the whole signalling exchange between the network and the mobile device and can be used to infer the location of every mobile phone with the highest possible spatial and temporal accuracy allowed by network-based data (see Ricciato et al., 2017). We monitor the number of phone records during the day (daily location from 09:00 to 15:00) and during the night from 23:00 to 05:59. A 2-week time series of VLR data was used in this study in order to reduce nonroutine localisations, aiming for spatial patterns in the average daily rhythm of human activity. We worked with a 10-day period for nighttime localisation (2-weeks period without weekends) and 6-day period for daytime localisation (Tuesday-Thursday) in order to reduce the impact of weekend activities on Friday and Monday. The resulting cell coverage area for work (daytime) and home (nighttime) localisation is estimated as the cell with the highest ratio of phone records. The resulting database consisted of approximately 8,000 'work' and 'sleep' locations (cell coverage centroids) of 822,165 unique phone IDs. The spatial distribution of daytime and nighttime localisation is shown in Figure 2;

3. Only the phone IDs with assigned daytime $(754,257)$ or nighttime $(536,976)$ localisation in Bratislava were subsequently used for temporal analysis in the spatial frame of population grids. We chose one particular day (Wednesday, 5.12.2018) and at every hour we identified the most frequent mobile cell for a particular phone ID. Subsequently we counted the number of unique phone IDs on the grid level. The advantage of the grid over irregular areal units is stability over time, whereas units devised for purposes such as census enumeration tend to be periodically revised and also to relate strongly to population distributions at specific times, such as the implicit connection between census geographies and nighttime residential population distributions (Martin et al., 2015, p. 757). To reduce the amount of noise due to locating errors, grids with the total number of users during the 24-hour period under 3,000 were excluded from analysis (according to empirical observation in remote areas). In most cases these grids were localised in non-urbanised areas outside the city limits; and

4. The final step was to analyse the rhythmic profile of every grid to integrate places of similar rhythmicity. The following features for defining the particular temporality type were considered: the peak time of mobile phone users' presence, the time of any secondary peak, the duration of peak presence and the time when the grid is abandoned.

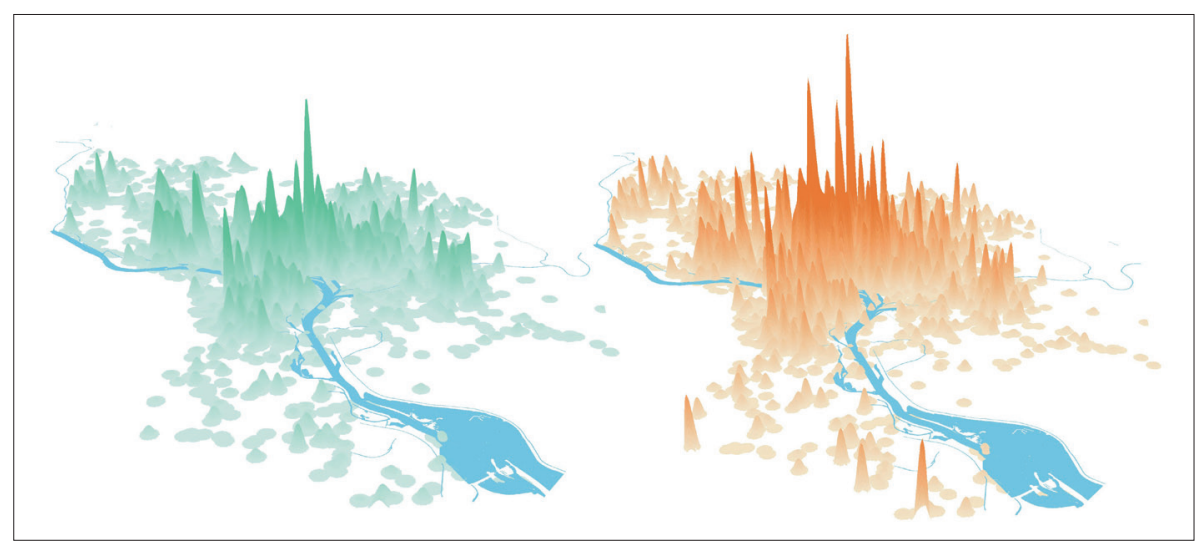

Fig. 2: Nighttime (left) and daytime (right) localisation of mobile phone users in Bratislava. Kernel density of the number of unique phone IDs with a long-term day and night localisation

Sources: (data) Market Locator SK: longitudinal signalling exchange data of Slovak Telekom, Orange Slovensko, O2 Slovakia $(N=822,165)$; authors' analysis

In spite of the apparent simplicity of the procedure, it is important to be aware of a number of limitations arising from the principles of mobile network operation and the legal conditions of mobile user data processing when interpreting mobile localisation data. We will try to highlight the most important ones:

i. The number of unique phone IDs cannot be reliably aligned with the number of people (individual users). The reason is that we cannot assume that every citizen has a mobile device, as well as we cannot exclude people using multiple SIM cards from the database;

ii. The mobile phone user may not be the same person as the phone holder. For example, within one family, children can use mobile phones registered to their parents. The underestimation of the child component in the mobile network user structure is a natural consequence of the mobile cellular subscription of the parents of children. Under-representation of seniors is a natural consequence of the aged-based digital divide (Neves and Amaro, 2012); iii. VLR data only roughly indicate the area that the cell or sector is serving. The spatial accuracy is contingent on the architecture of the mobile infrastructure (granularity of cell coverage areas), which depends on the type of antennas and the landscape surface (the smaller the cells, the better the location estimates). Within each technology $(2 \mathrm{G}, 3 \mathrm{G}$ and $4 \mathrm{G})$ the cell density determines the local network capacity, i.e. the maximum amount of data traffic that a network can deliver. Hence, the spatial granularity of cellular coverage depends on the density of mobile network/phone users, and on their traffic intensity. In the urban environment, it is in the range of hundreds of metres, in suburban and rural areas it can be in the range of kilometres;

iv. The lack of cell footprint information represents a serious disadvantage of the method used here. It can be expected that augmenting the method with accurate cell footprint information will improve the fidelity of the final result (cf. Ricciato et al., 2015); 
v. One specific feature of the Bratislava urban area is its position at the border with Austria and Hungary. Seamless handover between countries allows mobile phone users to enjoy continued voice and data connectivity across the border. This, however, brings an increased number of records for the mobile cells localised near the state border; and

vi. It should be pointed out that seasonal variations probably exist in the daily timing of human activity due to changes in driving factors, such as the length of daytime.

An important remark should be made about privacy issues in the method used here. Researchers cannot access mobile operators' raw data, so there is a "middle string" which prepares queries for end users such as companies, government users, or scientists. In Slovakia, the company Market Locator has a special contract with all three major mobile operators to mediate data distribution and to guarantee data security. This service ensures maximum anonymity of mobile phone users by presenting only aggregated data. All mobile phone users remained anonymous, so persons or their precise locations cannot be identified. The data structure is illustrated in Table 1. The attribute "subscriber_id" represents a unique identifier of the SIM card holder anonymised by a hash function, and the "cell_id" represents the BTS tower, where the position of a SIM card was recorded.

Ensuring secure access to data through a data processing company provides a unique opportunity to exploit the potential of mobile phone localisation data while maximising the anonymity of its users. By jointly analysing data from all major mobile network operators within the country, we significantly reduce the risk of under- or over-representing certain subsets of population or locations in cell-level data. It is important to remark that micro-data does not leave the mobile network operator domain.

\begin{tabular}{lccc}
\hline subscriber_id & date & hour & cell_id \\
\hline a5gfh78b5trf & $2018-12-05$ & 11 & 13590 \\
nj6j7kl9mn23 & $2018-12-05$ & 13 & 34568 \\
b5nh6sf7v35 & $2018-12-05$ & 5 & 8742 \\
\hline
\end{tabular}

Tab. 1. The structure of data used in this study Source: Market Locator SK

\section{Results: Bratislava's urban rhythms}

Bratislava has been the capital of the newly formed Slovak Republic since 1993. Today, although incomparable with its counterparts in neighbouring countries due to its modest size of about a half a million inhabitants, it has the capital city status and position that shape the spatialities of urban life and its rhythms. The modern development of the city was closely linked to industrial urbanisation, which was later underpinned by its growing importance as an administrative, political and cultural centre, being either the second city in Czechoslovakia or the capital of the independent Slovak Republic. Post-socialist transition brought once again important political and economic stimuli reshaping the spatio-temporalities of the city. Deindustrialisation, a booming service oriented economy (Ondoš and Korec, 2008) and growing administrative importance, have changed the rhythmicity of the former industrial town, influencing and influenced by daily commuting from a vividly developing hinterland due to massive suburbanisation (Šveda et al., 2016). Whereas the industrial city was characterised by a shared rhythm determined by dominant pacemakers (industrial plants) producing a rather uniform factory pattern, the deindustrialised city is associated with a significant weakening of such pacemakers cutting across the society, and thus with a distinctive individualisation of urban rhythmicity (Mulíček et al., 2016).

In order to identify the most significant urban rhythm types (chronopoles) present in the city, we start the analysis by examining the diurnal time use curve at the city level (see Fig. 3). The night minimum of phone users is not surprising, as it shows Bratislava as a natural centre of employment with intensive commuting. The number of unique phone IDs with a long-term daytime localisation exceeds the nighttime localisation by over 200,000 mobile phone users. The morning starts with a rapid rise between 6:00 and 7:00 am, which can be aligned with the commuting from the metropolitan region. In a previous analysis, more than 139,000 commuting mobile phone IDs were recorded in the metropolitan area of Bratislava (BID, 2019). During the daytime, the maximum number of urban users was recorded at 3:00 pm. The later daytime peak corresponds to postindustrial societies with servicesoriented employment (cf., Ahas et al., 2015). Although Bratislava is still in part an industrial city with dominant

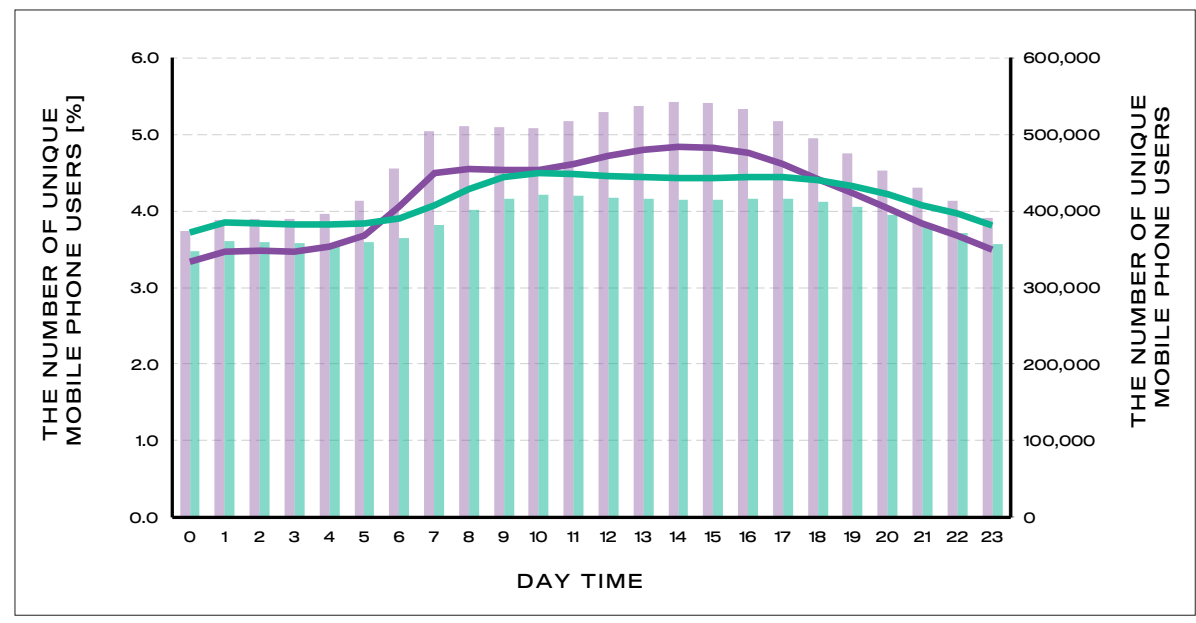

Fig. 3: Diurnal activity curve of selected days in Bratislava, Slovakia (purple: Wednesday 5.12.2018, green: Saturday 1.12.2018). Aggregated data for all network cells in Bratislava

Sources: (data) Market Locator SK: longitudinal signalling exchange data of Slovak Telekom, Orange Slovensko, O2 Slovakia $(N=822,165)$; authors' compilation 
car production, the central parts of the city represent an important commercial and administrative centre void of industry. This fact is probably behind the slower decline of logs' activity curve in the afternoon.

The recorded number of 'sleeping' mobile phone users $(536,976)$ suggests that there is a larger number of inhabitants living in Bratislava than the official statistics reports. Officially, according to permanent residency statistics (2018), 432,864 people reside in Bratislava, but this number has been long believed to be very unreliable. Still, we should take these estimates as a meaningful approximation of the population count rather than its precise quantification. Fundamentally, the number of unique phone IDs cannot be reliably aligned with the population density. There are several arguments which speak to the under- or overcounted numbers of the phone-based residential population. There are reasons for over-counted numbers arising from mobile communication, specifically in the case of companyowned cell phones. Especially in the business districts of Bratislava, we can expect a significant number of phones with business registration. As the distribution in Figure 2 shows, the central business district of Bratislava hosts the largest proportion of phone users with nighttime and daytime localisation. It is not easy, however, to differentiate between private and business-related communication of company-owned cell phones. Clearly, there is a significant share of company-owned cell phones and filtering those phones IDs would not be an ideal solution, as we could lose a significant number of localisation records (users). Other arguments relate to the under-representation of certain subsets of the population (children or seniors) or locations (small and remote settlements) in cell-level data.

Analysing the rhythmic profile of each grid (chronotope), the urban space of Bratislava can be regionalised into six categories - chronopoles. The basic characteristics of the particular types of chronopoles, identified according to their common rhythmic profiles, are provided in Figure 4. The fundamental difference between particular chronopoles is based on the peak and off-peak periods. The rhythms, stemming from the presence and absence of mobile phone users, are undoubtedly conditioned by the employment patterns of city users. Therefore, it is essential to include knowledge of the prevailing functions of every urban district. In order to understand the temporality of the individual urban grid, we have investigated the character of the urban environment and the potential underlying forces (pacemakers) behind spatio-temporal patterns and differences.

The resulting spatial distribution (see Fig. 5) presents the division of urban space into relatively consistent territory types (chronopoles). Central areas show the highest concentration of mobile phone users with the peak time at noon or afternoon, while areas on the outskirts feature lower number of mobile phone users, which culminate during the night.

Following the work of Mulíček et al. (2015), on the city level the daily work cycle combines the logic of two groups of pacemakers: 'clock-time pacemakers' and 'event-time

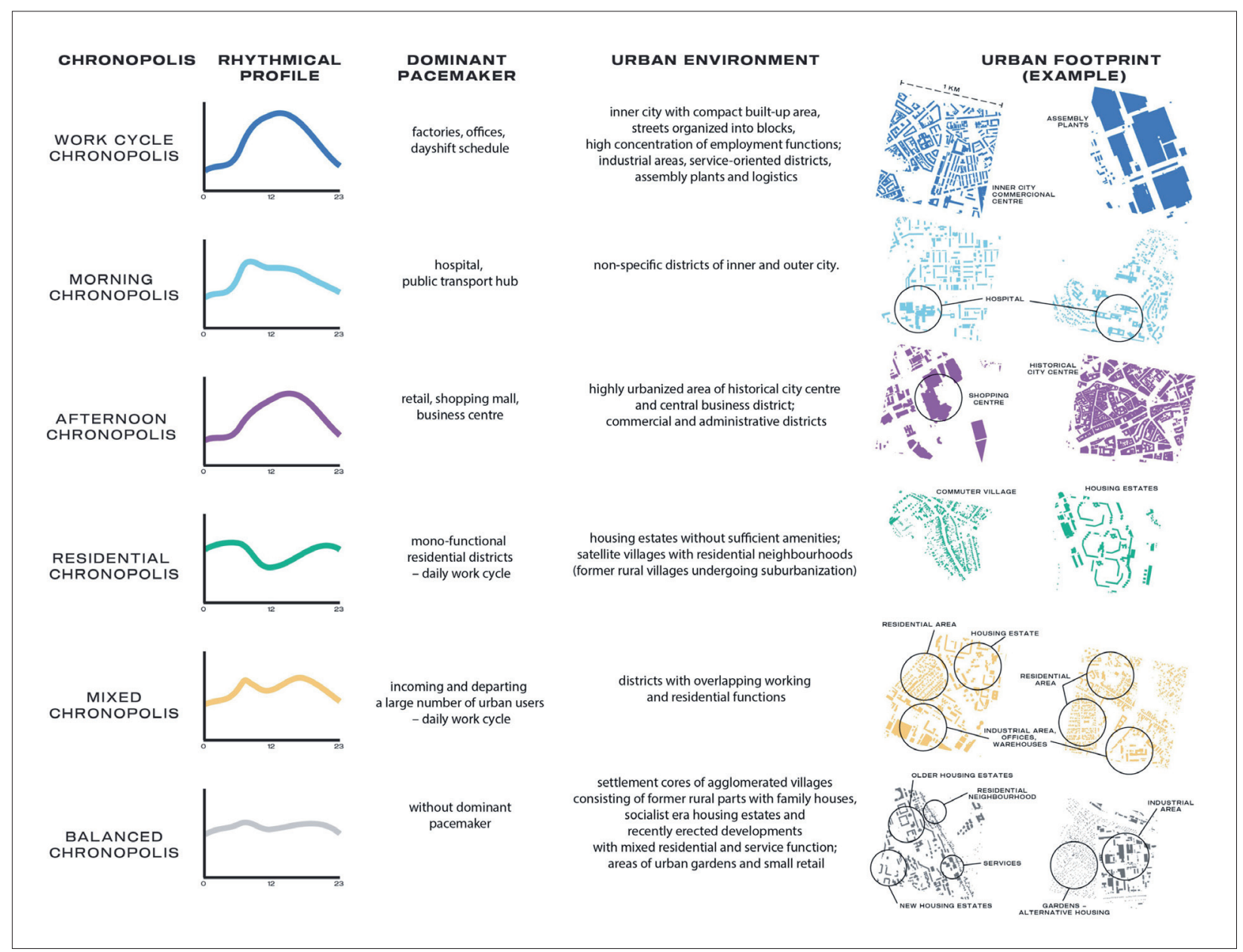

Fig. 4: The characteristics of grids with analogical rhythmic profiles - chronopoles (gridded hourly records of mobile phone users)

Source: authors' conceptualisation 


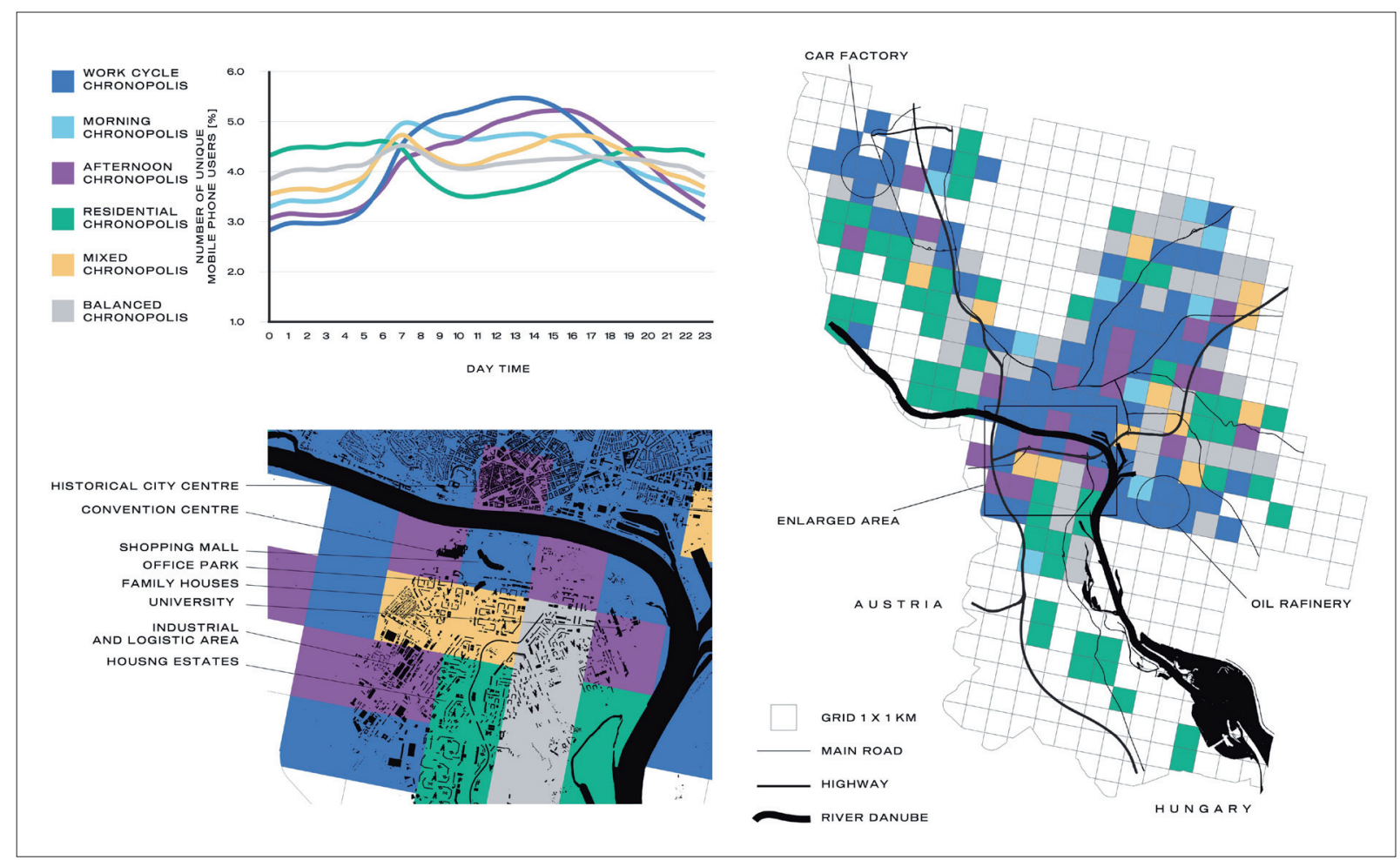

Fig. 5: The spatial distribution of grids with analogical rhythmic profiles - chronopoles. Gridded hourly records of mobile phone users

Sources: (data) Market Locator SK: longitudinal signalling exchange data of Slovak Telekom, Orange Slovensko, O2 Slovakia $(N=822,165)$; authors' compilations

pacemakers'. The first one specifies the time when the locality is abandoned or occupied. The second one describes the duration of the inhabitants' presence or absence. Pacemakers constitute stable sources of particular rhythms and we can identify various institutions, activities or structures that set the timing for a given urban environment. For instance, the hospital grounds are likely to define the morning peak in several grids within the 'Morning chronopolis'. The culmination of mobile phone localisations in morning hours is probably caused by the start of office hours with the highest number of patients waiting for examination. Another institutional pacemaker is the car factory (Volkswagen Slovakia) which is the largest employer in the Bratislava region. More than 10,000 employees are firmly bound by the work cycle of the factory, which manifested itself in the 'Work cycle chronopolis'. The same goes for the area of the oil refinery factory (Slovnaft) in the south-east part of Bratislava. The curve of this working type follows the morning and evening rush hour. Grids with a working type profile (A-shaped daily course) are most common, representing $30 \%$ of the units under investigation.

The healthcare and industrial areas can be assigned as 'clock-time pacemakers', which are determined by specific time-space points to which phone communications must be adapted (e.g. working hours). The second type of pacemaker - 'event-time pacemaker' - expresses a certain minimal, typical or maximum duration of an activity. Such pacemakers are associated with socially delimited durations applicable to certain situations or activities (Mulíček et al., 2015, p. 311). In this view, the shopping malls exhibit as a dominant component of an overall rhythm of the 'Afternoon chronopolis'. The typical shopping session usually takes time in the afternoon, moving the peak period to 4:00-5:00 pm. The extended opening hours of shops, restaurants and pubs, in effect reflect the historical city centre.
In several parts of the city a particular pacemaker is not recognisable at first sight due to various overlapping rhythms. The mixed character of the given urban area, which involves residential and non-residential areas, is the unifying element of a relatively heterogeneous group forming the 'Mixed chronopolis'. In this type of rhythmic profile, mobile phone users accumulate in the morning and afternoon hours featuring peaks at mobile network infrastructure. The arrival of residents and departure of workers is probably the key factor of unique (overlapping) temporality. The outlying residential neighbourhoods, especially the satellite villages influenced by suburbanisation during the last two decades, express the inverse presence-absence polarity compared to the time profile of work-related types. The poorly developed amenities and almost exclusively residential character of such areas force residents to leave in the morning and return in the afternoon, forming the typical U-shape daily course of the 'Residential chronopolis'. There is a slightly different shape of the curve for the grids representing the areas of residential suburbanisation and the socialist-era housing estates of the outer city. A more significant decrease of mobile phone IDs during the day was recorded in newly erected suburban areas, which may indicate the limited work-related opportunities. Besides that, the formerly monofunctional residential areas of housing estates have established shopping and services and have become the target for small and medium-sized enterprises.

The rhythms of residential districts, however, are not described by 'Residential chronopolis' exclusively. Several grids have recorded temporality without significant peaks. This 'balanced chronopolis' is the consequence of very different urban structures and activities. In certain instances, the balanced time profile is probably the result of mutual contradictory factors. In this case, the urban grid constitutes of central parts of former satellite villages, massively urbanised 
during the socialist era. Nowadays, these districts are formed from former rural parts with family houses, socialist-era housing estates and recently erected developments. Along with the housing, they provide various services and jobs and act as a secondary cores in the urban space. In the second group, the balanced daily course is probably the result of the low fluctuation of mobile phone users during the day. An example is a brownfield area neighbouring the locality of gardens and alternative housing. The common feature of these seemingly different urban environments is the absence of larger work-related institutions, which would be involved as dominant pacemakers.

Due to the complexity of human activity and the diversity of underlying driving forces, however, the examination of diurnal time use curves would need deeper analysis, including the monitoring of the mobile phone's trajectories throughout the day. It is also essential to acquire the prevailing function of every grid based on the empirical observation of employment structure. The Census in 2021 would be a great opportunity to test such a context.

\section{Discussion and conclusion}

Rhythmic patterns can be seen all around us, in all processes, including the everyday mobility of the city's population. One main objective of this paper was to develop a methodological procedure that uses the data from mobile network operators to analyse the rhythm of the city and to delimit temporally defined urban space as a typological category. This objective can be achieved by various analytical tools, most commonly at this time by call-detail-records of the mobile networks. In this paper we put forward an alternative approach that uses the longitudinal signalling exchange datasets of mobile networks, and converts them into the time-space localisation of city users in order to analyse the polyrhythmia of individual urban places (chronotopes). In order to test our approach, we used mobile phone data from Bratislava to analyse spatio-temporal differences within the city. The proposed workflow based on VLR data produces a replicable means for measuring temporal variation of differentiated urban environments. Our results show that a city's diurnal rhythm exhibits repeating temporal patterns along locally distinct spatio-temporal areas within the city (cf. Osman and Mulíček, 2017). Analysing the similarity of rhythmic profiles, we identified particular types of chronotopes, conceptualised as chronopoles. It is noteworthy that the differences between the urban places of high and low cell density (the granularity of cell coverage areas) have not weakened the ability to capture meaningful local-level rhythms.

The differences between particular chronopoles reflect the dispersion of the industrial and service sectors within the city area. Moreover, they correspond with the localisation of residential districts and their share of work-related functions. The rhythms of urban districts with dominant residential or industrial functions are characterised by the arrival and departure of large numbers of mobile phone users. Peak and off-peak periods correspond to the prevailing nature of the urban grid represented by the dominant pacemaker. The meaningful time profiles in a variety of urban contexts help to ensure that the proposed method for analysing urban rhythmicity is relevant across a wide range of spatio-temporal patterns and differences. The findings could provide a better insight with respect to our understanding of the daily routine of human activity and its geographical patterns in urban environments. Moreover, gridded hourly records of mobile phone users can be useful as urban monitoring tools and provide straightforward input to several models, particularly transport, land use, economic and environmental models of the city.

The analyses presented here confirm the great research potential of VLR data exploration compared to the traditional CDR data sets. At a given time, the VLR records the celllevel locations of all mobile devices, both active and idle. The observation of VLR records thus provides an instantaneous description of the location of all mobile devices at cell level. Moreover, the importance of this data source in spatiotemporal analysis is likely to increase. This is due to changes in mobile phone usage. While in the past we have used it mainly for voice calls and SMS messages, currently this use is declining in favour of data services (social networks, instant chat, etc.) and the passive use of the phone (e.g. in various applications which do not require an active interaction).

Despite the above-mentioned advantages, there are specific issues associated with the identification of daytime and nighttime localisation. It is clear that these categories only loosely describe the work-related and home-related anchors of individual time-space pathways. In fact, they involve a very diverse manifestation of everydayness. An important area for future research is therefore how traditional qualitative data can be used together with big data, such as mobile network datasets, for overcoming the limitations of the latter (Kwan and Schwanen, 2018). There are several types of data that would complement or enrich the analysis of urban rhythms and extend the interpretation of mobilenetwork data. Monitoring of the mobile phone user's activity throughout the day would be helpful, but such tracking would require the active cooperation of the mobile subscriber (see Ahas et al., 2010). Valuable sources of data are also traffic counters, footfall sensors or video tracking, which can measure temporal movement in greater detail. Nevertheless, the records of the signalling exchange are a representation of the various rhythmicities of a given area. This ability is close to Lefebvre's polyrhythmicity - a concept of numerous urban entities shaping, modulating, and synchronising rhythms (Lefebvre, 2004). In this view, any analysed localisation of mobile phone users constitutes a simple example of extensive social, economic or biological rhythms.

As Sui (2012, p. 13) mentions, Hägerstrand's holographic world view is not a special way of formulating problems, but rather a special way of forming an image before any questions can be asked. In this view, the massive amounts of data from the mobile network infrastructure (and various social media sites) are building a complex image of everydayness, but our research methods and analytical power are insufficient to generate more appropriate questions and answers. Yet, there is an urgent need to develop more robust data analysis and synthesis methods for studying time and space dynamics.

\section{Acknowledgments}

This work was supported by the Slovak Research and Development Agency under Contract No. APVV-16-0462, VEGA 2/0113/19 and KEGA 066UK-4/2020. The authors wish to acknowledge the company Market Locator SK for its support.

\section{References:}

AHAS, R., AASA, A., ROOSEA, A., MARK, Ü., SILMA, S. (2008): Evaluating passive mobile positioning data 
for tourism surveys: An Estonian case study. Tourism Management, 29(3): 469-486.

AHAS, R., AASA, A., SILM, S., TIRU, M. (2010): Daily rhythms of suburban commuters' movements in the Tallinn metropolitan area: Case study with mobile positioning data. Transportation Research Part C: Emerging Technologies, 18(1): 45-54.

AHAS, R., AASA, A., YUAN, Y., RAUBAL, M., SMOREDA, Z., LIU, Y., ZOOK, M. (2015): Everyday space-time geographies: Using mobile phone-based sensor data to monitor urban activity in Harbin, Paris, and Tallinn. International Journal of Geographical Information Science, 29(11): 2017-2039.

BAKHTIN, M. M. (1981): The Dialogic Imagination: Four Essays. Austin and London, University of Texas Press.

BAKHTIN, M. M. (2002): Forms of Time and of the chronotope in the novel: Notes toward a historical poetics. In: Richardson, B. [ed.]: Narrative Dynamics: Essays on Time, Plot, Closure, and Frames (pp. 15-24). Columbus, Ohio State University Press.

BENGTSSON L., LU, X., THORSON. A., GARFIELD, R., VON SCHREEB, J. (2011): Improved response to disasters and outbreaks by tracking population movements with mobile phone network data: a postearthquake geospatial study in Haiti, PLoS Medicine, 8(8): e1001083.

BID (2019). Analysis of mobile positioning data in Bratislava and Trnava region for internal purposes of Bratislava integrated transportation system. Internal analysis. Bratislava, Bratislava integrated transportation system.

BROMLEY, R. D. F., TALLON, A. R., THOMAS, C. J. (2003): Disaggregating the space - time layers of city-centre activities and their users. Environment and Planning A: Economy and Space, 35(10): 1831-1851.

CALABRESE, F., COLONNA, M., LOVISOLO, P., PARATA, D., RATTI, C. (2010): Real-time urban monitoring using cell phones: A case study in Rome. IEEE Transactions on Intelligent Transportation Systems, 12(1): 141-151.

CASTELLS, M., FERNANDEZ-ARDEVOL, M., QIU, J. L., SEY, A. (2009): Mobile communication and society: A global perspective. Cambridge, Mass.: MIT Press.

CRANG, M. (2001): Temporalised space and motion. In: May, J., Thrift, N [eds.]: Timespace: Geographies of Temporality (pp. 187-207). London, Routledge.

CROOKS, A., PFOSER, D., JENKINS, A., CROITORU, A., STEFANIDIS, A., SMITH, D., KARAGIORGOU, S., EFENTAKIS, A., LAMPRIANIDIS, G. (2015): Crowdsourcing urban form and function. International Journal of Geographical Information Science, 29(5): 720-741.

CSÁJI, B. C., BROWET, A., TRAAG, V.A., DELVENNE, J. C., HUENS, E., VAN DOOREN, P., BLONDEL, V. D. (2013): Exploring the mobility of mobile phone users. Physica A: statistical mechanics and its applications, 392(6): 1459-1473.

DEVILlE, P., LINARD, C., MARTIN, S., GILBERT, M., STEVENS, F. R., GAUGHAN, A. E., BLONDEL, V. D., TATEM, A. J. (2014): Dynamic population mapping using mobile phone data. Proceedings of the National Academy of Sciences, 111(45): 15888-15893.
EDENSOR, T. [ed.] (2012): Geographies of rhythm: nature, place, mobilities and bodies. Farnham, Ashgate Publishing, Ltd.

FOLCH-SERRA, M. (1990): Place, voice, space: Mikhail Bakhtin's dialogical landscape. Environment and Planning D: Society and Space, 8(3): 255-274.

GONZÁLEZ, M. C., HIDALGO, C. A., BARABÁSIM A. L. (2008): Understanding individual human mobility patterns. Nature, 453(7196): 779-782.

GOODCHILD, M. F., JANELLE, D. G. (1984): The city around the clock: Space-time patterns of urban ecological structure. Environment and Planning A: Economy and Space, 16(6): 807-820.

GRINBERGER, A. Y., SHOVAL, N. (2015): A temporalcontextual analysis of urban dynamics using locationbased data. International Journal of Geographical Information Science, 29(11): 1969-1987.

HÄGERSTRAND, T. (1970): What about people in regional science?. Papers of the Regional Science Association. 24 (1): 6-21.

ISAACMAN, S., BECKER, R., CÁCERES, R., KOBOUROV, S., MARTONOSI, M., ROWLAND, J., VARSHAVSKY, A. (2011): Identifying important places in people's lives from cellular network data. International Conference on Pervasive Computing (pp. 133-151). Berlin, Heidelberg, Springer.

JÄRV, O., AHAS, R., SALUVEER, E., DERUDDER, B., WITLOX, F. (2012): Mobile phones in a traffic flow: A geographical perspective to evening rush hour traffic analysis using call detail records. PLoS ONE, 7(11): $1-11$

KANG, C., LIU, Y., MA, X., WU, L. (2012). Towards estimating urban population distributions from mobile call data. Journal of Urban Technology, 19(4): 3-21.

KWAN, M. P., SCHWANEN, T. [eds.] (2018): Geographies of Mobility: Recent Advances in Theory and Method. Routledge.

LAGUERRE, M. (2003): Urban Multiculturalism and Globalization in New York City: An Analysis of Diasporic Temporalities. New York, Palgrave Macmillan.

LEFEBVRE, H. (2004): Rhythm analysis: Space, time and everyday life. London, Continuum.

MA, T., PEI, T., SONG, C., LIU, Y., DU, Y., AND LIAO, X. (2019): Understanding geographical patterns of a city's diurnal rhythm from aggregate data of location-aware services. Transactions in GIS, 23(1):104-117.

MARTIN, D., COCKINGS, S., LEUNG, S. (2015): Developing a flexible framework for spatiotemporal population modelling. Annals of the Association of American Geographers, 105(4): 754-772.

MULÍČEK, O., OSMAN, R. (2018): Rhythm of urban retail landscapes: Shopping hours and the urban chronotopes. Moravian Geographical Reports, 26(1): 2-13.

MULÍČEK, O., OSMAN, R., SEIDENGLANZ, D. (2015): Urban rhythms: A chronotopic approach to urban timespace. Time \& Society, 24(3): 304-325.

MULÍČEK, O., OSMAN, R., SEIDENGLANZ, D. (2016): Time-space rhythms of the city - The industrial and postindustrial Brno. Environment and Planning A, 48(1): 115-131. 
MULLER, P. O. (1982). Everyday life in suburbia: A review of changing social and economic forces that shape daily rhythms within the outer city. American Quarterly, 34 (3): 262-277.

NEMEŠKAL, J., OUŘEDNÍČEK, M., POSPÍŠILOVÁ, L. (2020): Temporality of urban space: daily rhythms of a typical weekday in the Prague metropolitan area. Journal of Maps, 16(1): 30-39.

NEVES, B., AMARO, F. (2012): Too old for technology? How the elderly of Lisbon use and perceive ICT. The journal of community informatics, 8(1): 1-12.

NOVÁK, J., TEMELOVÁ, J. (2012): Každodenní život a prostorová mobilita mladých Pražanů: pilotní studie využití lokalizačních dat mobilních telefonů. Czech Sociological Review, 48(5): 911-938.

ONDOŠ, S., KOREC, P. (2008): The rediscovered city: A case study of post-socialist Bratislava. Geografický časopis, 60(2): 199-213.

OSMAN, R., MULÍČEK, O. (2017): Urban chronopolis: Ensemble of rhythmized dislocated places. Geoforum, 85: $46-57$.

PAIVA, D. (2016): Collapsed rhythms: the impact of urban change in the everyday life of elders. Space and Culture, 19(4): 345-360.

RATTI, C., FRENCHMAN, D., PULSELLI, R., WILLIAMS, S. (2006): Mobile landscapes: Using location data from cell phones for urban analysis. Environment and Planning B: Planning and Design, 33: 727-748.

READES, J., CALABRESE, F., RATTI, C. (2009): Eigenplaces: Analysing cities using the space and time structure of the mobile phone network. Environment and Planning B: Planning and Design, 36: 824-836.

REMM, T., KASEMETS, K. (2019): Chronotope as a framework for landscape experience analysis. Landscape Research, 45(2): 254-264.

RICCIATO, F., WIDHALM, P., CRAGLIA, M., PANTISANO, F. (2015): Estimating population density distribution from network-based mobile phone data. Luxembourg, Publications Office of the European Union.

SAGL, G., DELMELLE, E., DELMELLE, E. (2014): Mapping collective human activity in an urban environment based on mobile phone data. Cartography and Geographic Information Science, 41(3): 272-285.
SILM, S. AHAS, R. (2014): The temporal variation of ethnic segregation in a city: evidence from a mobile phone use dataset. Social Science Research, 47: 30-43.

SONG, C., QU, Z., BLUMM, N., BARABÁSI, A. L. (2010): Limits of predictability in human mobility. Science, 327(5968): 1018-1021.

SUI, D. (2012): Looking through Hägerstrand's dual vistas: towards a unifying framework for time geography. Journal of Transport Geography, 23: 5-16.

ŠVEDA, M., KRIŽAN, F., BARLÍK, P. (2019): Využitie lokalizačných dát mobilnej siete $\mathrm{v}$ turizme: kto sú, kedy prichádzajú a kam smerujú zahraniční návštevníci na Slovensku? Geografický časopis, 71(3): 203-225.

ŠVEDA, M., MADAJOVÁ, M., PODOLÁK, P. (2016): Behind the differentiation of suburban development in the hinterland of Bratislava, Slovakia. Sociologický časopis/ Czech Sociological Review, 52(6): 893-925.

TAYLOR, P. J., PARKS, D. N. (1975): A Kantian view of the city: A factorial-ecology experiment in space and time. Environment and Planning A: Economy and Space, 7(6): 671-688.

TU, W., CAO, J., YUE, Y., SHAW, S. L., ZHOU, M., WANG, Z., LI, Q. (2017): Coupling mobile phone and social media data: A new approach to understanding urban functions and diurnal patterns. International Journal of Geographical Information Science, 31(12): 2331-2358.

WESOLOWSKI, A., EAGLE, N., TATEM, A. J., SMITH, D. L., NOOR, A. M., SNOW, R. W., BUCKEE, C. O. (2012): Quantifying the impact of human mobility on malaria. Science 338(6104): 267-270.

WIRTH, L. (1938): Urbanism as a Way of Life. The American Journal of Sociology 44(1): 1-24.

XIA, F., WANG, J., KONG, X., WANG, Z., LI, J., LIU, C. (2018): Exploring human mobility patterns in urban scenarios: A trajectory data perspective. IEEE Communications Magazine, 56(3): 142-149.

YUAN, Y., RAUBAL, M. (2016): Analyzing the distribution of human activity space from mobile phone usage: An individual and urban-oriented study. International Journal of Geographical Information Science, 30(8): 1594-1621. 